\title{
Blended Teaching Strategies for Art Design Major Courses in Colleges
}

\author{
https://doi.org/10.3991/ijet.v15i24.19033 \\ $\mathrm{Yu}$ Gao \\ Fine Arts College of Baoji University, Baoji, China \\ artmouse 515@163.com
}

\begin{abstract}
The blended teaching has not been well implemented in art design major courses of colleges. Neither has the performance of this teaching mode in course teaching been correctly evaluated. To solve the problem, this paper attempts to design suitable blended teaching strategies for art design major courses in colleges. To this end, a theoretical analysis was carried out on how blended teaching promotes the effects of modern art design education and course teaching. On this basis, several strategies were presented to implement blended teaching in art design major courses of colleges. From the perspective of engineering application, the authors established an evaluation index system and an evaluation analysis model for the performance of blended teaching in art design major courses, and thereby managed to quantify the teaching performance. The research results provide a theoretical basis and a practical solution for the implementation of blended teaching in art design major courses.
\end{abstract}

Keywords—Blended teaching, art design, colleges, course teaching

\section{$1 \quad$ Introduction}

Following the continuous development and in-depth application of modern intelligent education technology, the blended teaching has played an increasingly important role in modern education [1-3]. Research on the implementation and improvement of the blended teaching model in modern education is of great research significance for promoting the quality of modern education in terms of the strategies, methods, and approaches [4-6]. As an important part of modern education, art design has a promotive effect on the implementation of quality-oriented education. It is also a vital link in the training of professional art talents, proposing unique requirements for the blended teaching. Therefore, it has gradually become a hot issue in modern education to study the blended teaching of art design major courses [7-9]. Some scholars have carried out a series of related research, and obtained certain research results. For example, Rasheed Abubakar Rasheed et al. systematically analyzed and summarized the current problems and challenges of blended online learning [10]. Marciulyniene et al. [11] studied the practical teaching of art students, and discussed the interdisciplinary teaching mode among computer science students. Hallam et al. [12] took the English Waldorf Steiner school as a specific case and analyzed the art teaching methods. Yang et 
al. [13] researched and analyzed the quality evaluation of MOOC/SPOC-based hybrid teaching, and established a corresponding evaluation index system. Qi [14] conducted research and analysis on the training mode of teaching talents for art design majors in colleges, and explored the new mode for applied talent training in many aspects. Tu [15] applied a mixed method of quantitative and qualitative research to analyze the teaching mode of art courses, which provides a reference for the implementation of the blended teaching. However, the blended teaching is a relatively new modern education model, and faces multiple constraints during its implementation. Especially with the continuous development of modern intelligent education technology, the blended teaching shows a dynamic development trend, thus causing some systemic problems inevitably in this process, that is, the difficulty in selecting an appropriate implementation strategy and effectively evaluating the blended teaching performance, etc. To this end, the authors first summarized the existing research results, and discussed the blended teaching strategies of the art design major courses in colleges from the comprehensive perspectives of theoretical analysis and engineering application. Based on entropy method [16-19] and information axioms [20-23], the corresponding performance evaluation system and model were established.

This study consists of 5 sections. Section 1 introduces and analyzes the blended teaching in modern education, as well as related research issues about the application of blended teaching model in the art design major course; Section 2 discusses the promotion effect of the blended teaching on modern art design education and course teaching; Section 3 studies the implementation strategies of the blended teaching for art design major; Section 4 further explores the evaluation system and model for the performance of the blended teaching in art design major course; Section 5 gives the research conclusions.

\section{The Promotion Effect of Blended Teaching on Modern Art Design Education and Course Teaching}

The blended teaching is a comprehensive teaching mode, providing support for modern art design education and course teaching from a multi-faceted perspective. Therefore, the rational use of the blended teaching is non-negligible. Specifically, it's manifested in the following aspects.

\subsection{Promoting the reform of modern art design education}

In essence, the blended teaching in the art design major means to redesign and consider the relationship between teaching and learning. This teaching-learning relationship has always been a field involved more in the modern art education reforms, and needs to keep up with the pace of modern education. In the teaching of art design major courses, the traditional teacher-oriented teaching model has always been criticized, while the blended teaching is teacher-led and student-oriented, emphasizing the enthusiasm and initiative of art students in the learning process, and combines various teaching methods such as group cooperation to cultivate their creativity, cooperation, 
and independent learning. Meanwhile, the development of modern smart technology also provides supports for the reform of modern art education. The implementation of a blende teaching model in art design major courses can give full play to the advantages of modern intelligent technology, combine art design offline teaching with online network teaching, and maximize the teaching effect of art design courses. This is also in line with the trend of modern art design education reform. In addition, judging from its application scope, the blended teaching model can not only be applied to the field of vocational education and training, but also is valued by international research institutions and widely used in higher education. It conforms to the values of traditional higher education institutions, and tends to be one of the important trends in promoting higher education reform in the coming years due to the provable potential and meaningful learning experiences. The research report issued by the U.S. Department of Education also stated that, compared to pure classroom face-to-face teaching and distance online learning, the blended teaching is the most effective way. Thus, the blended teaching is much conducive to the implementation and development of modern art education reform.

\subsection{Improving the classroom teaching effect of modern art design major}

The core of the classroom teaching reform in art design major courses is to ensure the learning initiative of students, thereby changing the traditional lecture-style teaching method of art teachers. The art teachers in classroom are responsible for inspiring and guiding students to think and explore problems. The blended teaching in the art design course can change the traditional classroom teaching-centered model, and emphasizes the combination of dominant and subject roles. Traditional classroom teaching of art design courses is mostly based on simple teaching, i.e., teachers play a dominant role in the teaching and transmission of knowledge, only as the porter of art professional knowledge. Whereas, under the blended teaching mode, the main responsibility of the art design teacher is to organize and guide, i.e., lead students to explore knowledge, cultivate students' critical thinking, and develop their awareness of knowledge inheritance and ability of innovation. They need to think more about what students need, which is just an important content of modern higher education reform of classroom teaching. Online teaching platforms such as MOOC, flipped classroom, cloud classroom, etc., as the catalysts for classroom teaching reform, have been combined with offline teaching in the blended teaching. Using the advantages of the two teaching modes, the blended teaching can truly give play to the dominant role of students in the classroom, and then effectively improve the classroom teaching effect of art design major.

\subsection{Facilitating the deep learning of art students}

The blended teaching of art design major courses is a mixture of online learning and offline teaching methods. It's also a mixture of different teaching theories-based models (such as constructivism, behaviorism, and cognitivism) at a deeper level to achieve the most ideal teaching effect, involving both student participation and teach- 
er-led activities. Mainly guided by constructivism and mastery learning theory, the blended teaching in art design major makes comprehensive use of modern educational technology and a variety of teaching methods, and adopts the mode of first self-study and then discussion which is more in line with the laws of human cognition. It plays a very important role in inspiring the emotional experience of students, promoting effective questioning and active learning, and improving the knowledge construction. Also, this mode can integrate the learning and application according to the characteristics of different professional courses, and combine abstract art design professional theoretical knowledge with related activities to achieve better learning and application, which is conductive to expand the relatively narrow coverage of traditional teaching knowledge of art design major to a certain extent, and help the art design majors to effectively use various knowledge sources for the integration of art professional knowledge. Under the blended teaching, most of the relatively elementary learning goals such as memory and comprehension are completed in online learning, and students with strong abilities can even complete the analysis and application of some knowledge learned offline. Art teachers can cultivate students' application and analysis ability and comprehensive ability by organizing small projects in groups etc., and finally train their evaluation ability through mutual evaluation between groups. From this perspective, the blended teaching mode implemented in art design major course teaching can effectively promote students' deep learning of the knowledge they have learned and achieve higher learning goals.

\subsection{Motivating the development of high-quality teaching resources for art design major}

With the emergence of Internet technology-based online courses, especially MOOC, flipped classrooms, and cloud classrooms, etc., modern education has paid more attention to star-teacher classrooms and elite-school classrooms. Although the online course development mechanism is not yet complete, and some college teachers do not agree with or adapt to the new teaching model, it's still a general trend to integrate online courses into the modern education course teaching system. No matter whether it's from the perspective of teachers improving their own reputation, or of schools improving social reputation and attracting better quality students, high-quality teaching resources are the most useful means. Therefore, actively developing highquality teaching resources will be more conducive to improving the teaching quality of art design major courses. At present, some colleges or alliances focus on the research and development of high-quality educational resources. Through the integration and allocation of teachers and resources in several universities, the maximum distribution of educational resources has been achieved. In addition, various forms of effective operating modes have also been developed during the educational resource sharing. For the current operating mechanisms of MOOC, flipped classroom, cloud classroom, etc., cooperation and alliances are often used to jointly develop courses and share high-quality resources, thus forming a world-wide learning community. This has a great enlightening effect on the blended teaching of art design major courses, and is also more conducive to the development of high-quality teaching resources 
for art design majors, providing more sources of professional knowledge for the teaching of art design majors, and enriching the teaching content.

\subsection{Implementing the teaching evaluation and information feedback of art design art courses}

Considering the diversity of the teaching forms in art design major, the evaluation of blended teaching has always been a hot topic of research. For example, in the course teaching of some majors, the professional teacher requires students to compile the logical relationship diagram of the course content according to their own understanding at the end of the class; students can fully express their understanding and opinions, and complete it through the discussion with their classmates, which is then scored by the teachers accordingly. This indicates that in art design course teaching, the blended teaching is conducive to the summarization and sorting of professional knowledge points, which not only consolidate professional knowledge of art students, but also cultivate their own logical thinking and autonomous learning awareness; their teamwork skills are also cultivated through communication with classmates, and the evaluation of professional teachers is relatively fair. Thus, it is a multi-purpose teaching evaluation method of art design course. Furthermore, the application of blended teaching in the art design courses can help to establish a team of teaching assistants for supervision and Q\&A on the online platform, and assist teachers in encouraging students to participate in offline classroom discussions for enhancing the learning experience and learning effects. And with the continuous development of modern intelligent technology, some intelligent evaluation systems have begun to appear. The mid-term and final exams and assessments are carried out through a combination of online and offline, which can not only accurately test the students' mastery of the professional content, but also analyze some errors and give reasonable evaluation and analysis. This has a very important role in guiding students to improve their professional learning ability.

\section{$3 \quad$ Blended Teaching Strategies for Art Design Major Courses}

From the above, the blended teaching has an important role in promoting the teaching quality of art design major courses. Therefore, it's very important to design the proper blended teaching strategies in the art design major. The authors proposed the following strategies.

\subsection{Expanding the function application of the teaching platforms in art design major}

The teaching platform functions of art design course are mixed. On this basis, first the course platform column or function item of art design major should be designed in a concise and clear manner, making it convenient for art design students to operate and learn. If the teaching platform is too complicated and cumbersome, it will affect 
the emotion and enthusiasm of the students, and even cause their rebellious psychology. Secondly, the design of resources and functions such as the learning content, learning methods, testing of learning results, and the generation and feedback of test results etc. of art design courses should be coherent and continuous. In this way, the art design students can conduct continuous learning to improve learning efficiency, and understand the results, find problems, and correct errors in time. At the same time, it's necessary to make full use of the student learning management system, teacher teaching management system, and educational administration supervision system of art design major course, and timely feedback the data information to achieve the purpose of supervising and motivating students.

\subsection{Enriching the construction of online resources for art design major course}

The construction of online resources is the basis for the development of the blended teaching model in art design major, and it is also an important link and part in the implementation of the blended teaching. Teaching resources are related materials that support students to complete various learning activities and tasks. The design of highquality teaching resources can reduce the cognitive burden of students in learning and improve their learning efficiency. Therefore, it is necessary to make full use of the country's excellent digital education resources, which can not only guarantee the quality and scientific nature of art design course resources, but also promote the development of online teaching content. The pros and cons of online teaching resources for art design major courses directly affect the quality of blended teaching. According to the overall requirements for the construction of art design major courses, the online resources of blended teaching should help increase students' interest and promote their understanding, mastering and application of relevant professional knowledge and principles. For this reason, the online resources for art design major courses should be diversified. First, the types of resources should be diversified, i.e., the types of resources can include text, pictures, audio, video, and animation, etc., completing each other's advantages of various resources; multi-dimensional resources are used to stimulate students' multiple senses and thinking. Secondly, the form of resources should be visualized. The knowledge such as abstract principles, structure, and procedures etc. should be visualized in the forms of video or animation as much as possible. Then, the introduction of projects or tasks should be interesting, so that art and design students can have curiosity and desire to explore, and then stimulate their learning enthusiasm and initiative. Finally, the content of resources should be refined; the teaching content presented on the platform should be the most important of unit teaching, rather than copying the content of art design professional textbooks, let students spend the least time to acquire more valuable professional knowledge and ability.

\subsection{Enhancing online teaching ability of art design major courses}

Online teaching is the basic link of the blended teaching in art design major. The art design teachers should make full use of the diverse resources of the art design course teaching platform, and design different personalized projects or learning tasks for students with different abilities and intelligence types, to ensure that every student 
has gains and progress. For the students who have made progress and gains, professional teachers should promptly affirm and praise through the platform system. First, professional teachers can assign tasks to students, let them carry out independent learning and discussion about tasks, and closely integrate the tasks to be completed with the problems to be solved, to enhance the learning purposiveness and pertinence of students, and conduct the online learning in a faster, more efficient, and more accurate way. This shall help to realize the internal transfer of professional knowledge of art design and the cultivation of students' advanced thinking ability, enable them to understand and learn about the use of professional knowledge, and improve their enthusiasm, initiative and learning efficiency. Secondly, professional teachers should supervise and guide students' learning using the blended teaching model on the basis of students' autonomous learning, and pay attention to their learning dynamics and progress in time. Thus, the teachers find problems, and then enlighten and guide students to solve in a timely and appropriate way through interaction, while students can continuously develop a sense of gain during the problem-solving process, thereby enhancing students' motivation and confidence in learning.

\subsection{Improving the offline classroom teaching effect of art design major courses}

The offline classroom teaching effect of art design major courses should be improved in the following aspects. Firstly, the selection and design of the offline teaching content should be made according to the online teaching content and students' learning situation, that is, offline teaching is the extension of online teaching, while online teaching is the foundation of offline teaching. The key point of offline teaching is to test the students' mastery of relevant knowledge and theory in online learning by allowing them to complete related tasks or solve related practical problems. The difficult point is the way of guiding students to solve problems in the process of completing tasks. The online and offline teaching content should be closely linked. In offline learning, art design teachers teach professional knowledge, guide students to use the learned knowledge and implement tasks, and conduct a summary evaluation of learning. Secondly, the offline classroom teaching methods for art design courses should be determined according to the characteristics of the teaching content and the cognitive ability of students. Generally, the practice, discussion, and case methods etc. are used in the study of principle and method-related knowledge; project-based teaching, and field teaching methods etc. are applied to learn about structural, procedural, and operational knowledge. In addition, offline classroom teaching of art design major courses should be targeted. Various situations and problems that occur in related learning should be pointed out as much as possible, so that students can not only understand the types of problems, but also analyze the root cause, and find the best solution.

\subsection{Deepening the evaluation and feedback mechanism for the course teaching of art design major}

The teaching evaluation and feedback mechanism of art design major courses should be deepened as follows. At first, it's necessary to intelligentize the evaluation 
tools of art design course. Art design teachers should fully utilize the data-driven evaluation methods to collect and analyse the data information of students in online learning and interaction, and then adopt special tools to evaluate the factors that affect students' learning results. They can also evaluate student performance and provide timely feedback to students by audio or video tools. Timely evaluation and feedback can help teachers to effectively understand students' current learning status and knowledge mastery, strengthen students' active learning behaviours, and correct negative learning attitudes. Teachers can also use the supervision and management functions of the teaching platform to keep abreast of students' learning in class. Second, the evaluation content of art design major courses should be diversified. Art design teachers can use sensor technology and learning analysis technology to intelligently locate, identify, track, and record learners' learning data in flexible learning space and time, fully record and quantify the learning process information, scientifically measure and interpret the hidden learning intensity that students are difficult to capture in the learning process, predict potential problems and hidden dangers, and provide a basis for teaching decision-making. Furthermore, the evaluation subjects need to be multiple; it includes online course learning content, homework, and test completion of art design courses, participation in forum discussions, and attendance of live courses and discussion courses, classroom performance, completion of practical project, and final test scores, etc.; on the other hand, as well as the teachers and teaching administrators' evaluation of students, and the mutual evaluation between students. Finally, the teaching evaluation process of art design major courses needs to be dynamic. The evaluation purpose is to promote students to learn knowledge, practice skills, constantly surpass themselves, and constantly climb new heights. Therefore, the evaluation of students should be made in a process-oriented and dynamic way, and the learning process of students should also be evaluated; also, students are allowed to perform multiple dynamic tests until they are satisfied.

\section{Performance Analysis for The Blended Teaching of Art Design Major Courses}

\subsection{Principles in selecting performance indicators}

In order to effectively measure the promotion effect of the blended teaching on the art design course, it is necessary to reasonably select the performance indicators and achieve an accurate and appropriate performance analysis result. In this paper, the performance indicators were selected based on the following principles:

1. Scientificity and rationality: The selected performance indicators must have clear scientific meanings and can reasonably represent the essential problems for performance analysis.

2. Objectivity and authenticity: The selected performance indicators should be selected based on objective facts, avoiding subjective guesswork, and the true situation of performance analyses should be expressed.

3. Comprehensiveness and systematicness: The selected performance indicators must reflect the attributes at different levels, and have good logic and system. 
4. Easy analysis and easy operation: The selected performance indicators should make it easier to obtain relevant performance analysis values, and carry out effective qualitative and quantitative analysis, to obtain highly reliable analysis results.

\subsection{Establishment of the performance evaluation index system}

Table 1. Performance evaluation index system

\begin{tabular}{|c|c|c|}
\hline System layer & Primary indicators & Secondary indicators \\
\hline \multirow{33}{*}{$\begin{array}{l}\text { The evaluation index } \\
\text { system for the blended } \\
\text { teaching performance } \\
\text { of the art design major } \\
\text { course }\end{array}$} & \multirow{4}{*}{ Teaching ability } & Basic professional ability \\
\hline & & Professional curriculum planning ability \\
\hline & & Teaching innovation ability \\
\hline & & Teaching team building ability \\
\hline & \multirow{4}{*}{ Teaching methods } & Instructiveness \\
\hline & & Continuity \\
\hline & & Scientificity \\
\hline & & Enlightenment \\
\hline & \multirow{3}{*}{ Teaching means } & Intelligence \\
\hline & & Diversity \\
\hline & & Pertinence \\
\hline & \multirow{2}{*}{ Teaching forms } & Rationality \\
\hline & & Innovativeness \\
\hline & \multirow{3}{*}{ Teaching content } & Richness \\
\hline & & Advancement \\
\hline & & Integrativeness \\
\hline & \multirow{6}{*}{ Teaching effect } & Classroom teaching atmosphere \\
\hline & & Interaction after class \\
\hline & & Cultivation of students' autonomous learning ability \\
\hline & & Cultivation of students' innovation ability \\
\hline & & Clarity of teaching objectives \\
\hline & & Completeness of teaching task \\
\hline & \multirow{4}{*}{ Teaching assessment } & Perfectness of the assessment mechanism \\
\hline & & Student satisfaction \\
\hline & & Teacher mutual evaluation satisfaction \\
\hline & & Expert supervision satisfaction \\
\hline & \multirow{7}{*}{ Teaching results } & The level and quantity of teaching awards \\
\hline & & $\begin{array}{l}\text { The level and quantity of education reform projects } \\
\text { undertaken }\end{array}$ \\
\hline & & The level and quantity of student competition awards \\
\hline & & Pass rate \\
\hline & & Student excellence rate \\
\hline & & Grade and quantity of high-quality textbooks \\
\hline & & $\begin{array}{l}\text { Grade and quantity of published educational reform } \\
\text { papers }\end{array}$ \\
\hline
\end{tabular}

Based on the above principles, this paper establishes an evaluation index system for the blended teaching performance of the art design major course. This system mainly consists of different performance indicators such as teaching ability, teaching 
methods, teaching means, teaching forms, teaching content, teaching effects, teaching assessment and teaching results, as shown in Table 1.

\subsection{Fuzzy information calculation model for performance analysis}

Information axiom is an important part of axiomatic design theory [24-25]. On this basis, the less information contained in the design factors of a complex system, the better the design system. And, the amount of information I contained in the design factors can be expressed as

$$
I=-\log _{2} P
$$

And, $\mathrm{P}$ is the probability that the current design factors meet the given design requirements.

Under special circumstances, if the discrete parameters are required to achieve the given design of the design system, the probability can often be determined through the relevant degree of membership, namely,

$$
P=\int_{\mu_{1}}^{\mu_{2}} \rho(P) d P
$$

where, $\mu 1$ and $\mu 2$ respectively represent the limit values of the probability that the design factor meets the given design requirements, and $\rho(\mathrm{P})$ is the probability density function, which generally shows random distribution.

Based on the performance evaluation index system established above, it can be seen that the performance indicators for the blended teaching effect of art design major courses were divided into qualitative indicators and quantitative indicators, or into positive indicators and negative indicators. Then, the corresponding index information calculation models were established respectively. Supposing that there are $\mathrm{m}$ analysis objects and $\mathrm{n}$ performance indicators; if the $\mathrm{j}$-th performance indicator is a quantitative indicator, its value for the i-th analysis object is $\mathrm{v}(\mathrm{ij})$; if it's a positive indicator, its standardized measurement value is $\mathrm{u}(\mathrm{ij})$, that is

$$
u(i j)=\frac{v(i j)-\min _{1 \leq i \leq m} v(i j)}{\max _{1 \leq i \leq m} v(i j)-\min _{1 \leq i \leq m} v(i j)}
$$

If it's a negative indicator, its normalized value is $\mathrm{u}(\mathrm{ij})$, that is

$$
u(i j)=\frac{\max _{1 \leq i \leq m} v(i j)-v(i j)}{\max _{1 \leq i \leq m} v(i j)-\min _{1 \leq i \leq m} v(i j)}
$$

Then, the amount of information I(ij) about the $\mathrm{j}$-th performance indicator of the ith analysis object is given as: 


$$
I(i j)=-\log _{2} P=\log _{2} e^{1-|u(i j)-\underset{1 \leq i \leq m}{\max u(i j)}|}
$$

If the $\mathrm{j}$-th performance indicator is a qualitative index, its value for the $\mathrm{i}$-th analysis object is generally expressed by fuzzy membership $\varphi(\mathrm{ij})$; if it is a positive indicator, the amount of information I(ij) is given as:

$$
I(i j)=-\log _{2} P=\log _{2} e^{1-\varphi(i j)}
$$

If it is a negative indicator, the amount of information I(ij) is expressed as:

$$
I(i j)=-\log _{2} P=\log _{2} e^{\varphi(i j)}
$$

\subsection{Generation of performance indicator weights based on entropy weight method}

Regardless of different types of performance indicators, it's assumed that the value of the corresponding indicator is expressed as $\mathrm{u}(\mathrm{ij})$ for the convenience of analysis. According to the theory of system decision analysis, different performance indicators have different degrees of importance. For this reason, these indicators need to be weighted. Entropy weight method has the characteristics of simple calculation, strong objectivity, and high accuracy in the process of index weight analysis. Thus, it was adopted to assign the weights for performance indicators.

On the basis of obtaining the value u(ij) of performance indicators, it can be calculated as:

$$
G(i j)=u(i j) / \sum_{i=1}^{m} u(i j)
$$

Then the information entropy $\mathrm{Hj}$ of the $\mathrm{j}$-th performance indicator is given as:

$$
H_{j}=-\frac{1}{\ln m} \sum_{i=1}^{m}(G(i j) * \ln G(i j))
$$

The absolute weight $\widetilde{w}_{j}$ of this indicator is calculated as:

$$
w_{j}=1-H_{j}
$$

From this, its relative weight wj can be derived as:

$$
w_{j}=w_{j} / \sum_{j=1}^{n} w_{j}
$$




\subsection{Algorithm implementation of performance analysis}

After obtaining the information amount I(ij) and relative weight wj, the comprehensive information amounts I(i) of the $\mathrm{i}$-th analysis object in the performance evaluation system of the blended teaching for art design major course can be given as:

$$
I(i)=\sum_{j=1}^{n}\left(w_{j} * I(i j)\right)
$$

According to the physical meaning of information axioms, the smaller the amount of comprehensive information I(i), the better the teaching effect of the art design major course under the blended teaching mode for the i-th analysis object; conversely, the greater the amount of information I(i), the worse the teaching effect of the said course. Therefore, the principle of preference is shown as:

$$
I(o)=I_{C}(k)=\min _{1 \leq i \leq m} I(i), 1 \leq k \leq m
$$

This indicates that the blended teaching for the k-th analysis object in art design major course performs the best.

\section{Conclusion}

The authors first analysed the implementation of the blended teaching in modern education, and confirmed its role in promoting modern art design education and course teaching. Then, specific strategies were presented to implement the blended teaching in modern art design education and course teaching, which provides directive guidance for the implementation of the said model in art design major courses. Finally, the evaluation index system and information axiom-based calculation models were established, to effectively evaluate the teaching performance of art design major course under the blended teaching model. This provides an important means of support for the performance evaluation of blended teaching in modern art design major courses.

\section{References}

[1] Jonker, H., März, V., Voogt, J. (2018). Teacher educators' professional identity under construction: The transition from teaching face-to-face to a blended curriculum. Teaching and Teacher Education, 71(4): 120-133. https://doi.org/10.1016/j.tate.2017.12.016.

[2] Porter, J.E., Barbagallo, M.S., Peck, B., Allen, L., Tanti, E., Churchill, A. (2020). The academic experiences of transitioning to blended online and digital nursing curriculum. Nurse Education Today, 87: 104361. https://doi.org/10.1016/j.nedt.2020.104361.

[3] Gao, L., Yuan, Y.H., Sun, H., Liu, Y. (2020). Practical study on the construction of college English blended teaching mode based on rain classroom: Taking Mudanjiang Medical Col- 
lege as an example. China Medical Education Technology, 34(4): 493-497. https://doi.org/ 10.13566/j.cnki.cmet.cn61-1317/g4.202004023.

[4] Sun, Y., Liang, D. (2019). Research on multi mixed teaching mode based on MOOC. Education Modernization, 6(87): 298-300. https://doi.org/10.16541/j.cnki.2095-8420.2019.87. $\underline{108}$.

[5] Wang, Y.G., Qi, X.J., Niu, S.D., Li, X., Wang, Y., Zhao, H.Y. (2020). Practice of mixed teaching mode of physiology based on SPOC + flipped classroom. Basic Medical Education, 22(7): 493-495. https://doi.org/ 10.13754/j.issn2095-1450.2020.07.09.

[6] Grenfell, J. (2013). Immersive interfaces for art education teaching and learning in virtual and real world learning environments. Procedia-Social and Behavioral Sciences, 93: 11981211. https://doi.org/10.1016/j.sbspro.2013.10.016.

[7] Hu, B. (2020). On the teaching strategies of art education in colleges and universities. Education Modernization, 7(33): 177-180. http://dx.doi.org/10.16541/j.cnki.2095-8420.2020 .33 .046 .

[8] Liu, N., Bu, Q.Q., Deng, R.P. (2020). The Exploration and Practice of the Mixed Teaching of the Chemical Technology Course Promoted by the Combination of OBE Concept with Online Resources. Education Modernization, 7(42): 53-56. http://dx.doi.org/10.16541/j. cnki.2095-8420.2020.42.014.

[9] Zhong, X.H. (2018). Analysis and reform of Guzheng teaching mode in art colleges from the perspective of new media Research. Education Modernization, 5(52): 87-89. https:// doi.org/ 10.16541/j.cnki.2095-8420.2018.52.034.

[10] Rasheed, R.A., Kamsin, A., Abdullah, N. A. (2020). Challenges in the online component of blended learning: A systematic review. Computers \& Education, 144: 103701. https:// doi.org/10.1016/j.compedu.2019.103701.

[11] Marciulyniene, R., Butrime, E., Melninkaite, V., Valteryte, R. (2014). Research of art students practical teaching, organizing interdisciplinary groups with computer sciences students. Procedia-Social and Behavioral Sciences, 122: 172-178. https://doi.org/10.1016/ j.sbspro.2014.01.1322.

[12] Hallam, J., Egan, S., Kirkham, J. (2016). An investigation into the ways in which art is taught in an English Waldorf Steiner school. Thinking skills and creativity, 19: 136-145. https://doi.org/10.1016/j.tsc.2015.07.003.

[13] Yang, C.X., Wang, H.T., Huang, Y.W. (2020). Study on Quality Evaluation of MOOC/SPOC Based Blended Teaching. Education Modernization, 7(41): 10-13. http://dx. doi.org/10.16541/j.cnki.2095-8420.2020.41.003.

[14] Qi, X.L. (2018). Research on the Training Mode of Teaching Talents in College Art Design Major. Hunan Packaging, 33(6): 39-41. https://doi.org/10.19686/j.cnki.issn1671-49 97.2018.06.009.

[15] Tu, J.W. (2020). Research on art education in Quanzhou based on mixed research method. Chinese Music, 2020(1): 162-168. https://doi.org/10.13812/j.cnki.cn11-1379/j.2020.01.021

[16] Cavallaro, F., Zavadskas, E.K., Streimikiene, D., Mardani, A. (2019). Assessment of concentrated solar power (CSP) technologies based on a modified intuitionistic fuzzy topsis and trigonometric entropy weights. Technological Forecasting and Social Change, 140: 258-270. https://doi.org/10.1016/j.techfore.2018.12.009.

[17] Allahverdyan, A.E., Galstyan, A., Abbas, A.E., Struzik, Z.R. (2018). Adaptive decision making via entropy minimization. International Journal of Approximate Reasoning, 103: 270-287. https://doi.org/10.1016/j.ijar.2018.10.001.

[18] Velázquez-Martinez, O., Kontomichalou, A., Santasalo-Aarnio, A., Reuter, M., Karttunen, A.J., Karppinen, M., Serna-Guerrero, R. (2020). A recycling process for thermoelectric 
devices developed with the support of statistical entropy analysis. Resources, Conservation and Recycling, 159: 104843. https://doi.org/10.1016/j.resconrec.2020.104843.

[19] Benedetto, F., Mastroeni, L., Quaresima, G., Vellucci, P. (2020). Does OVX affect WTI and Brent oil spot variance? Evidence from an entropy analysis. Energy Economics, 89: 104815. https://doi.org/10.1016/j.eneco.2020.104815.

[20] Kahraman, C., Cebi, S., Onar, S.C., Oztaysi, B. (2018). A novel trapezoidal intuitionistic fuzzy information axiom approach: An application to multicriteria landfill site selection. Engineering Applications of Artificial Intelligence, 67: 157-172. https://doi.org/10.1016/j. engappai.2017.09.009.

[21] Kahraman, C., Onar, S.C., Cebi, S., Oztaysi, B. (2017). Extension of information axiom from ordinary to intuitionistic fuzzy sets: an application to search algorithm selection. Computers \& Industrial Engineering, 105: 348-361. https://doi.org/10.1016/j.cie.2016.12.0 12.

[22] Seiti, H., Hafezalkotob, A., Fattahi, R. (2018). Extending a pessimistic-optimistic fuzzy information axiom-based approach considering acceptable risk: Application in the selection of maintenance strategy. Applied Soft Computing, 67: 895-909. https://doi.org/10.10 16/j.asoc.2017.11.017.

[23] Maghsoodi, A.I., Mosavat, M., Hafezalkotob, A., Hafezalkotob, A. (2019). Hybrid hierarchical fuzzy group decision-making based on information axioms and BWM: Prototype design selection. Computers \& Industrial Engineering, 127: 788-804. https://doi.org/10.10 16/j.cie.2018.11.018.

[24] Verma, A., Maiti, J., Boustras, G. (2020). Analysis of categorical incident data and design for safety interventions using axiomatic design framework. Safety science, 123: 104557. https://doi.org/10.1016/j.ssci.2019.104557.

[25] Karatas, M. (2020). Hydrogen energy storage method selection using fuzzy axiomatic design and analytic hierarchy process. International Journal of Hydrogen Energy, 45(32): 16227-16238. https://doi.org/10.1016/j.ijhydene.2019.11.130.

\section{$7 \quad$ Author}

Gao Yu is a teacher at Baoji College of Arts and Sciences. She specializes in design practice research, responsible for visual communication design teaching. Her research focuses on the reform and innovation of art design teaching methods.

Article submitted 2020-10-03. Resubmitted 2020-10-27. Final acceptance 2020-10-28. Final version published as submitted by the authors. 